\title{
Fusion of a Mandibular Third Molar and a Distomolar in a Trinidadian Child: Report of a Rare Case Diagnosed Using CBCT
}

\author{
Anne Kowlessar ${ }^{1 *}$, Kevin Henry ${ }^{2}$, Arlana Bissoon ${ }^{2}$, Trudee Hoyte1 \\ ${ }^{1}$ School of Dentistry, Child Dental Health Unit, The University of the West Indies, St. Augustine, Trinidad \\ ${ }^{2}$ School of Dentistry, Oral Diseases Unit, The University of The West Indies, St. Augustine, Trinidad \\ Email: ^annekowlessar@gmail.com
}

How to cite this paper: Kowlessar, A., Henry, K., Bissoon, A. and Hoyte, T. (2021) Fusion of a Mandibular Third Molar and a Distomolar in a Trinidadian Child: Report of a Rare Case Diagnosed Using CBCT. Open Journal of Stomatology, 11, 271-277. https://doi.org/10.4236/ojst.2021.118024

Received: June 28, 2021

Accepted: August 2, 2021

Published: August 5, 2021

Copyright $\odot 2021$ by author(s) and Scientific Research Publishing Inc. This work is licensed under the Creative Commons Attribution International License (CC BY 4.0).

http://creativecommons.org/licenses/by/4.0/

\begin{abstract}
Double teeth refer to two teeth that are totally or partially joined by dentin and maybe their pulps. These developmental anomalies may be the result of either gemination or fusion. This is a case of a 15-year-old Indo-Trinidadian male who presented with the fusion of a mandibular third molar with a distomolar as an incidental finding. The patient had his general dental care provided by a paediatric dentist and was referred to an oral and maxillofacial radiologist, orthodontist, and oral surgeon for consultation. A Cone-beam CT was taken to supplement the plain film periapical and orthopantomogram radiographs. It showed the three-dimensional orientation of the double molar and the extent of joining. This is the first case of fusion of a mandibular third molar to a distomolar being reported in the Caribbean.
\end{abstract}

\section{Keywords}

Double Molar, Distomolar, Fusion, Cone-Beam Computed Tomography, Trinidad

\section{Introduction}

Double teeth refer to two teeth that are totally or partially joined by dentin and maybe their pulps. These developmental anomalies may be the result of either gemination or fusion. Gemination is thought to be the result of the incomplete division of one tooth germ, and fusion is thought to arise from the union of two separate tooth germs. The aetiology of gemination remains unclear. However, several factors have been proposed to attribute to its development such as environmental factors, trauma, systemic diseases, vitamin deficits, genetic predispo- 
sition [1], and racial determinants has also been found to be a factor [2].

Dental anomalies detection should immediately alert the dentist towards considering the presence of undiagnosed medical conditions or syndromes [3] [4]. Several genetic syndromes have been associated with dental anomalies: Hallermann-Streiff syndrome, Fabry disease, Ehlers-Danlos syndrome, Apert syndrome, Crouzon syndrome, Zimmermann-Laband syndrome, Ellis-van Creveld syndrome, Robinow cleidocranial dysplasia, Oculofaciocardiodental syndrome, familial adenomatous polyposis; trichorhinophalangeal syndrome, Rubinstein-Taybi syndrome, Nance-Horan syndrome and Opitz BBB/G syndrome [5].

Supernumerary teeth refer to teeth that are additional to the usual number in the jaws. Distomolars are located distal to third molars and are generally within the line of the arch [6]. Distomolars are more common in the maxilla [7]. When fusion occurs between a normal tooth and a supernumerary tooth, it can be challenging to differentiate from germination [8] [9]. Fusion is believed to be related to physical forces or pressure that provokes close contact between developing teeth. However, its exact aetiology is unknown [9]. The prognosis of double teeth is usually poor as they can cause aesthetic distress, clinical complications such as the increased risk for caries, periodontal disease, delayed or ectopic teeth eruption [10].

It is integral to identify these anomalies because they may require surgical removal due to abnormal morphology and excessive mesiodistal width, which can cause orthodontic problems related to spacing and alignment [11] [12] [13]. Thus, a multidisciplinary approach to management is required in these cases, often with the inclusion of advanced, three-dimensional diagnostic imaging to accurately plan the surgical approach, localize the exact position of the anomaly, and confirm fusion rather than the presence of two separate teeth superimposed on each other on the two-dimensional views [14]. There have been few reported cases of fusion of mandibular third molars and distomolars described in the literature [15]. This case report aims to describe the rare incidental finding of fusion of a mandibular third molar to a distomolar in a child and to highlight the need for a multidisciplinary approach to treatment planning in such cases.

\section{Case Report}

A 15 year old East Indian male presented to a specialist paediatric dentist office for a dental check-up and prophylaxis. His mother reported that he had not been to the dentist for several years, but he complains of bleeding gums when brushing his teeth. An additional complaint was "crooked" teeth, and his parents wanted advice on having his teeth straightened out. His past dental history revealed only dental prophylaxis more than eight years ago. Moreover, it was revealed that his family are irregular dental attendees. His medical history revealed a double left urethra with mild to moderate hydronephrosis. Additionally, his sibling brother was diagnosed with hydronephrosis.

Extraoral examination was unremarkable. Intraoral examination's main find- 
ings were generalized swelling, erythema, and bleeding of the gingiva. This, in conjunction with the heavy plaque and calculus, confirmed a diagnosis of marginal gingivitis. A dental charting of teeth present revealed a missing lower left central incisor and no dental caries or existing restorations.

The patient presented with a Class 2 division 1 malocclusion on a Class 2 skeletal base. He had an increased overjet and reduced overbite. His right buccal segment and left canines were Class 1 . The left buccal segment was Class 3. This patient had bimaxillary protrusion with increased vertical proportions. There was severe, mandibular anterior and right posterior crowding. The mandibular right second and third molars were impacted.

An Orthopantomogram (OPG) was prescribed for the patient, which revealed a developing supernumerary distomolar in the left mandibular third molar region, which appeared to share the same crypt of the third molar with the two crowns being fused (Figure 1). However, it was unclear whether the crowns of the third molar and distomolar were definitively fused or whether the appearance was due to superimposition. Thus, a Cone Beam Computed Tomography (CBCT) scan was requested to assess the anomaly in three dimensions.

The CBCT scan confirmed fusion of the crown of the mesially inclined lower left third molar with a distomolar supernumerary and that there was one crypt around the anomaly (Figure 2 and Figure 3). Both teeth appeared to be developing separate roots. The pulp chambers were also separate at the current stage of development. The anomaly was in proximity (just superior) to the inferior dental canal. Additionally, there was dilaceration of the mesial root of the left mandibular second molar.

The patient was given oral hygiene instructions as recommended by the American Dental Association. A fluoride varnish treatment was also completed to reduce the risk of caries. In addition, dietary advice was given to the patient, which included reducing sugary food and drinks.

His orthodontic management would entail the extraction of all four first premolars with the placement of fixed appliances. A transpalatal arch and lingual arch will be placed for anchorage. The lower right second molar will be assessed to see how well it uprights, and if this position does not improve, it will be

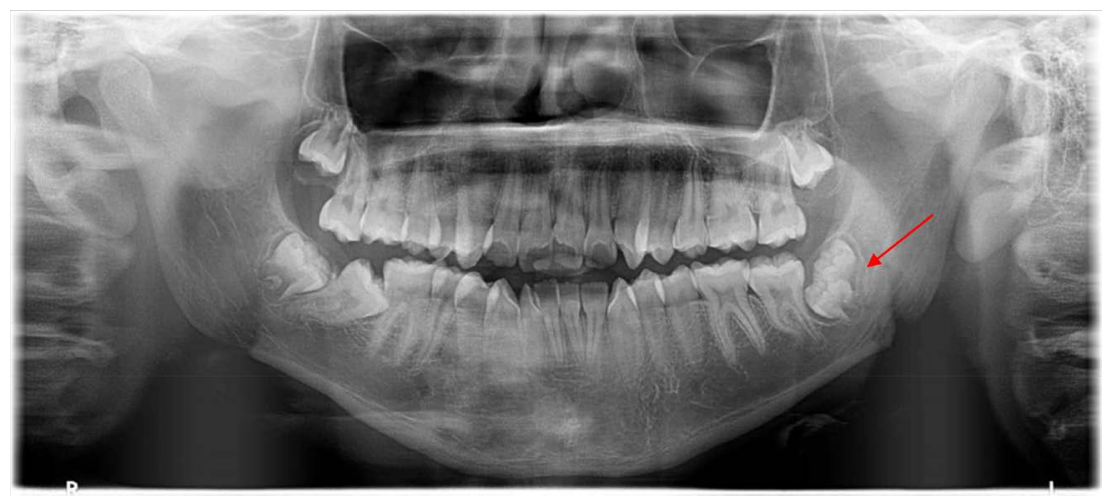

Figure 1. Dental panoramic radiograph showing fused left mandibular third molar and distomolar (arrowed). 


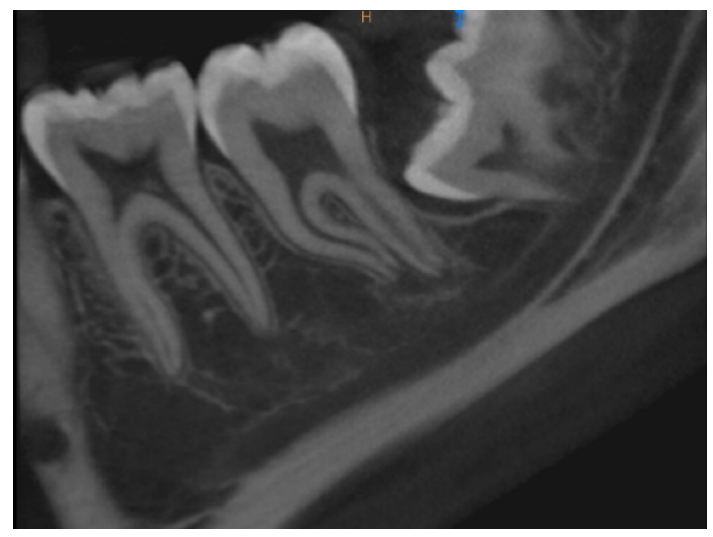

Figure 2. Curved CBCT reconstruction of left mandible showing fusion of enamel and dentine of the lower left third molar to the distomolar supernumerary.

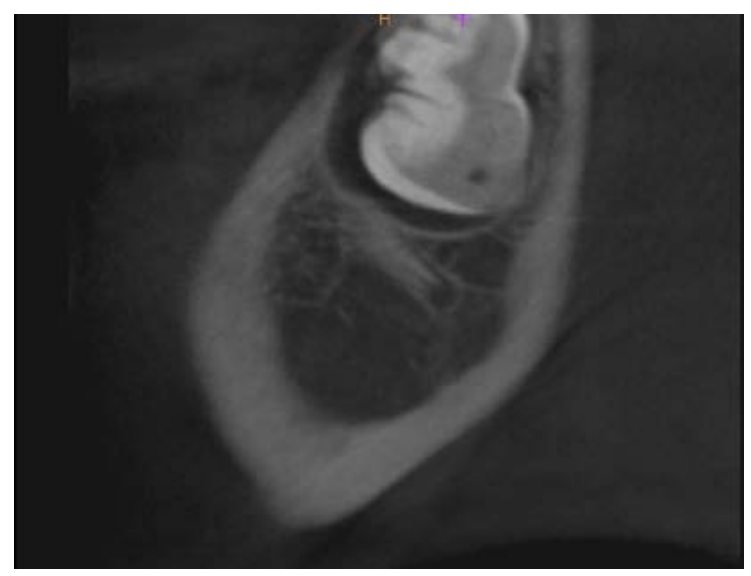

Figure 3. Sagittal section of CBCT of the left side of the mandible showing a single crypt, around the anomaly.

extracted at the same time as the lower left double molar teeth.

\section{Discussion}

This case of fusion of a third molar to a supernumerary molar tooth was a rare incidental finding on radiographic examination. Fusion can be described as the union between two individual developing teeth via dentin and/or enamel [16]. The precise aetiology is unknown. There is an equal preponderance amongst males and females [17]. The fusion of mandibular molar teeth to supernumerary teeth, particularly in the third molar region, remains an uncommon dental anomaly. Although fusion may occur in any dental arch region, it is more frequent in the premaxilla [15] [18]. The prevalence of fused teeth in the permanent dentition is $0.2 \%$ (unilateral) and $0.05 \%$ (bilateral) [19]. Noteworthy is that fusion commonly affects incisors, particularly the maxillary central incisors (3.6\%) and then the mandibular third molars (0.9\%) [14] [17]. This patient presented with a double left urethra and mild to moderate hydronephrosis. Urethral duplication is a congenital abnormality and is a rare finding amongst urinary tract malformations. There have been approximately 300 cases of urethral du- 
plication reported in the literature [20] [21]. The precise cause of this malformation is still uncertain. There are no cases in the reported literature of a patient presenting with urethral duplication with associated dental anomalies.

In the case presented, conventional radiographs were insufficient for assessing the anatomical extent of the dental anomaly in question. Three-dimensional imaging continues to provide the dental team with a myriad of information that supports appropriate treatment planning. Determining a differential diagnosis for these types of dental anomalies can be challenging. In the present case, the $\mathrm{CBCT}$ not only confirmed the presence and nature of the anomaly but also revealed proximity to the inferior dental canal and the presence of a dilacerated adjacent tooth root. Additionally, the use of CBCT to aid in surgical planning has been reported in the literature [22]. The potential risks of fused molar teeth on eruption are pericoronitis, dental caries, and periodontal infection [23]. Thus early removal of this patient's double molar should be considered. Incomplete root development of double molar may provide of ease of extraction. This action may reduce risk of paraesthesia to inferior alveolar nerve and relapse of orthodontic treatment.

The case presented above required a multidisciplinary approach to achieve an appropriate diagnosis and subsequent treatment planning. The disciplines involved included a paediatric dentist, orthodontist, oral radiologist and an oral surgeon. The role of advanced imaging is highlighted to allow for adequate treatment planning and execution.

\section{Conclusion}

This case report emphasizes the usefulness of three-dimensional dental imaging in the diagnosis and treatment planning of some cases and highlights the need for a multidisciplinary approach to the management of patients with dental anomalies.

\section{Conflicts of Interest}

The authors declare no conflicts of interest regarding the publication of this paper.

\section{References}

[1] Tomizawa, M., Shimizu, A., Hayashi, S. and Noda, T. (2002) Bilateral Maxillary Fused Primary Incisors Accompanied by Succedaneous Supernumerary Teeth: Report of a Case. International Journal of Paediatric Dentistry, 12, 223-227. https://doi.org/10.1046/j.1365-263X.2002.00351.x

[2] Santos, L.M., Forte, F.D. and Rocha, M.J. (2003) Pulp Therapy in a Maxillary Fused Primary Central Incisor-Report of a Case. International Journal of Paediatric Dentistry, 13, 274-278. https://doi.org/10.1046/j.1365-263X.2003.00464.x

[3] Desiate, A. and Milano, V. (1998) Dental Anomalies in Some Hereditary Syndromes Observed by the Authors. Minerva Stomatologica, 47, 361-366.

[4] Bailleul-Forestier, I., Berdal, A., Vinckier, F., de Ravel, T., Fryns, J.P. and Verloes, A. 
(2008) The Genetic Basis of Inherited Anomalies of the Teeth. Part 2: Syndromes with Significant Dental Involvement. European Journal of Medical Genetics, 51, 383-408. https://doi.org/10.1016/j.ejmg.2008.05.003

[5] Lubinsky, M. and Kantaputra, P.N. (2016) Syndromes with Supernumerary Teeth. American Journal of Medical Genetics Part A, 170, 2611-2616.

https://doi.org/10.1002/ajmg.a.37763

[6] Menardía-Pejuan, V., Berini-Aytés, L. and Gay-Escoda, C. (2000) Supernumerary Molars. A Review of 53 Cases. Bulletin du Groupement International Pour la Recherche Scientifique en Stomatologie \& Odontologie, 42, 101-105.

[7] Shahzad, K.M. and Roth, L.E. (2012) Prevalence and Management of Fourth Molars: A Retrospective Study and Literature Review. Journal of Oral and Maxillofacial Surgery, 70, 272-275. https://doi.org/10.1016/j.joms.2011.03.063

[8] Tsesis, I., Steinbock, N., Rosenberg, E. and Kaufman, A.Y. (2003) Endodontic Treatment of Developmental Anomalies in Posterior Teeth: Treatment of Geminated/Fused Teeth-Report of Two Cases. International Endodontic Journal, 36, 372-379. https://doi.org/10.1046/j.1365-2591.2003.00666.x

[9] Neville, B.W., Allen, C.M. and Bouquet, J.E. (2002) Oral and Maxillofacial Pathology. 2nd Edition, WB Saunders, Oxford.

[10] Duncan, W.K. and Helpin, M.L. (1987) Bilateral Fusion and Gemination: A Literature Analysis and Case Report. Oral Surgery, Oral Medicine, Oral Pathology, 64, 82-87. https://doi.org/10.1016/0030-4220(87)90121-6

[11] Kokten, G., Balcioglu, H. and Buyukertan, M. (2003) Supernumerary Fourth and Fifth Molars: A Report of Two Cases. The Journal of Contemporary Dental Practice, 4, 67-76. https://doi.org/10.5005/jcdp-4-4-67

[12] Delany, G.M. and Goldblatt, L.I. (1981) Fused Teeth: A Multidisciplinary Approach to Treatment. The Journal of the American Dental Association, 103, 732-734. https://doi.org/10.14219/jada.archive.1981.0396

[13] Hülsmann, M., Bahr, R. and Grohmann, U. (1997) Hemisection and Vital Treatment of a Fused Tooth-Literature Review and Case Report. Endodontics \& Dental Traumatology, 13, 253-258. https://doi.org/10.1111/j.1600-9657.1997.tb00051.x

[14] Pace, A., Sandler, P.J. and Murray, A. (2013) Macrodont Management. Dental Update, 40, 18-20, 23-26. https://doi.org/10.1111/j.1600-9657.1997.tb00051.x

[15] Turell, I.L. and Zmener, O. (1999) Endodontic Therapy in a Fused Mandibular Molar. Journal of Endodontics, 25, 208-209. https://doi.org/10.1016/S0099-2399(99)80144-7

[16] Lucey, S., Heath, N., Welbury, R.R. and Wright, G. (2009) Case Report: Cone-Beam CT Imaging in the Management of a Double Tooth. European Archives of Paediatric Dentistry, 10, 49-53. https://doi.org/10.1007/BF03262702

[17] Hamasha, A.A. and Al-Khateeb, T. (2004) Prevalence of Fused and Geminated Teeth in Jordanian Adults. Quintessence International, 35, 556-559.

[18] Graziani, F., Cei, S., Tonetti, M., Paolantonio, M., Serio, R., Sammartino, G., et al. (2010) Systemic Inflammation Following Non-Surgical and Surgical Periodontal Therapy. Journal of Clinical Periodontology, 37, 848-854. https://doi.org/10.1111/j.1600-051X.2010.01585.x

[19] Morris, D.O. (1992) Fusion of Mandibular Third and Supernumerary Fourth Molars. Dental Update, 19, 177-178.

[20] Mane, S.B., Obaidah, A., Dhende, N.P., Arlikar, J., Acharya, H., Thakur, A., et al. (2009) Urethral Duplication in Children: Our Experience of Eight Cases. Journal of 
Pediatric Urology, 5, 363-367. https://doi.org/10.1016/j.jpurol.2009.01.006

[21] Wani, S.A., Munianjana, N.B., Jadhav, V., Ramesh, S., Gowrishankar, B.C. and Deepak, J. (2019) Urethral Duplication in Children: Experience of Twenty Cases. Journal of Indian Association of Pediatric Surgeons, 24, 275-280.

https://doi.org/10.4103/jiaps.JIAPS $164 \quad 18$

[22] Ferreira-Junior, O., de Avila, L.D., Sampieri, M.B., Dias-Ribeiro, E., Chen, W.L. and Fan, S. (2009) Impacted Lower Third Molar Fused with a Supernumerary ToothDiagnosis and Treatment Planning Using Cone-Beam Computed Tomography. International Journal of Oral Science, 1, 224-228.

https://doi.org/10.4248/IJOS09056

[23] Kumar, D.A., Srivastava, R., Ali, I., Wadhwani, P. and Singh, H. (2015) Fused Mandibular Third Molar with Supernumerary Tooth: A Rare Case Report. Indian Journal of Oral Sciences, 6, 26-29. https://doi.org/10.4103/0976-6944.154606 